\title{
O sítio Jabuti, em Bragança, Pará, no cenário arqueológico do litoral amazônico
}

\author{
Site Jabuti, in Bragança, State of Pará, in the archaeological \\ scenario of the Amazonian coastal landscape
}

\author{
Maura Imazio da Silveira!', Elisangela Regina de Oliveira', Dirse Clara Kern'1, \\ Marcondes Lima da Costa ", Suyanne Flávia Santos Rodrigues "I \\ 'Museu Paraense Emílio Goeldi. Belém, Pará, Brasil \\ "Universidade Federal do Pará. Belém, Pará, Brasil
}

\begin{abstract}
Resumo: Quarenta anos após a conclusão do Projeto Salgado, no nordeste paraense, arqueólogos retomam pesquisas na região, investigando questões relacionadas a ocupações humanas pré-coloniais do litoral. São apresentados os primeiros resultados da pesquisa no sítio arqueológico Jabuti, localizado no município de Bragança (PA), na Reserva Extrativista Marinha CaetéTaperuçu. Trata-se de um sítio cerâmico, a céu aberto, do tipo habitação, com manchas de terra preta arqueológica. $\bigcirc$ material coletado constitui-se, principalmente, de fragmentos de cerâmica, alguns líticos lascados e corantes. A datação única C14 obtida indica que o sítio foi ocupado há pelo menos 2.900 anos BP. Interessante notar que, segundo esta datação, a ocupação ocorreu no segundo momento do modelo estabelecido por Pedro Walfir Martins Souza Filho e colaboradores, em artigo publicado em 2009, sobre a evolução geológica da zona bragantina do litoral do Salgado, ou seja, o sítio estava situado na maior ilha de terra, próximo ao continente. As características observadas no material cerâmico desse sítio remetem à tradição cerâmica Mina. Inicialmente, duas hipóteses são levantadas: 1) a ocorrência de cerâmica Mina neste tipo de sítio arqueológico pode indicar alguma forma de contato entre grupos sambaquieiros e outros grupos ceramistas; ou, ainda, 2) uma mudança na economia e no modo de vida dos grupos sambaquieiros em direção ao cultivo.
\end{abstract}

Palavras-chave: Arqueologia. Litoral amazônico. Terra Preta Arqueológica. Grupos ceramistas. Cerâmica Mina. Sambaqui.

Abstract: Forty years after completing the archaeological investigations in the Salgado region, northeastern Pará, researchers have returned to the site to study prehistoric human occupations in the northern coastal regions of Brazil near the Amazon estuary. This article presents the first results of archaeological research at the site Jabuti, located in the Caeté-Taperuçu Marine Extractive Reserve in the municipality of Bragança. This is an open-air residential site with anthropogenic dark earths ('terra preta de índio') and ceramic remains. The archeological remains consist mostly of fragments of pottery, as well as some flaked stone tools and dye residues. The sole C14 date obtained indicates that the site was occupied at least 2,900 years BP. According to this timing, the occupation occurred in the second stage of the model established by Pedro Walfir Martins Souza Filho and collaborators, in a paper published in 2009, for the geological evolution of the Bragança zone along the Salgado coast. Thus the site was situated on the largest soil-bearing island near the mainland. The ceramic material of this site belongs to the Mina tradition. Initially two hypotheses are proposed: 1) the Mina pottery indicates contact between shell midden groups and other ceramic-making groups, or 2) shell midden groups have begun a shift in their subsistence pattern towards cultivation.

Keywords: Archaeology. Amazon Coast. Amazonian dark earth. Ceramist groups. Mina pottery. Shell mounds.

SILVEIRA, Maura Imazio da; OLIVEIRA, Elisangela Regina de; KERN, Dirse Clara; COSTA, Marcondes Lima da; RODRIGUES, Suyanne Flávia Santos. O sítio Jabuti, em Bragança, Pará, no cenário arqueológico do litoral amazônico. Boletim do Museu Paraense Emílio Goeldi. Ciências Humanas, v. 6, n. 2, p. 335-345, maio-ago. 2011.

Autor para correspondência: Maura Imazio da Silveira. Museu Paraense Emílio Goeldi. Coordenação de Ciências Humanas. Av. Perimetral, 1901. Terra Firme. Belém, PA, Brasil. CEP 66077-830 (mauraslvr@yahoo.com).

Recebido em 16/11/2010

Aprovado em 30/06/2011

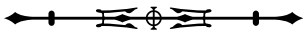




\section{CONTEXTO ARQUEOLÓGICO DA REGIÃO DO SALGADO, LITORAL NORDESTE DO PARÁ}

A área litorânea do estado do Pará é recortada por profundas reentrâncias na linha costeira e inúmeras ilhas, separadas do continente e entre si por canais ou furos de marés, ocupados por sistemas estuarinos. Denominada de Salgado, esta microrregião se estende da baía do Marajó à foz do rio Gurupi, no nordeste do estado (Simões, 1981). As principais baías formadas pelos estuários dos mais importantes rios que drenam esta região são as de Maracanã, Pirabas, Japerica, Quatipuru, Caeté e Gurupi (Figura 1).
A paisagem do litoral do Salgado estabeleceuse sobre terrenos do Terciário (depósitos marinhos da Formação Pirabas, subaflorantes, e sedimentos fluviolacustres do Grupo Barreiras, parcialmente aflorantes) e do Quaternário (areias, siltes e argilas, como depósitos fluviais, lacustres, de manguezais e mesmo marinhos). O clima quente e úmido é regido pela dicotomia entre a estação seca, o verão, entre os meses de julho e novembro, e a estação chuvosa, que corresponde ao inverno e predomina entre janeiro e maio. A temperatura oscila entre a máxima de $30^{\circ} \mathrm{C}$ e a mínima de $22^{\circ} \mathrm{C}$ (Pará, 2007a).

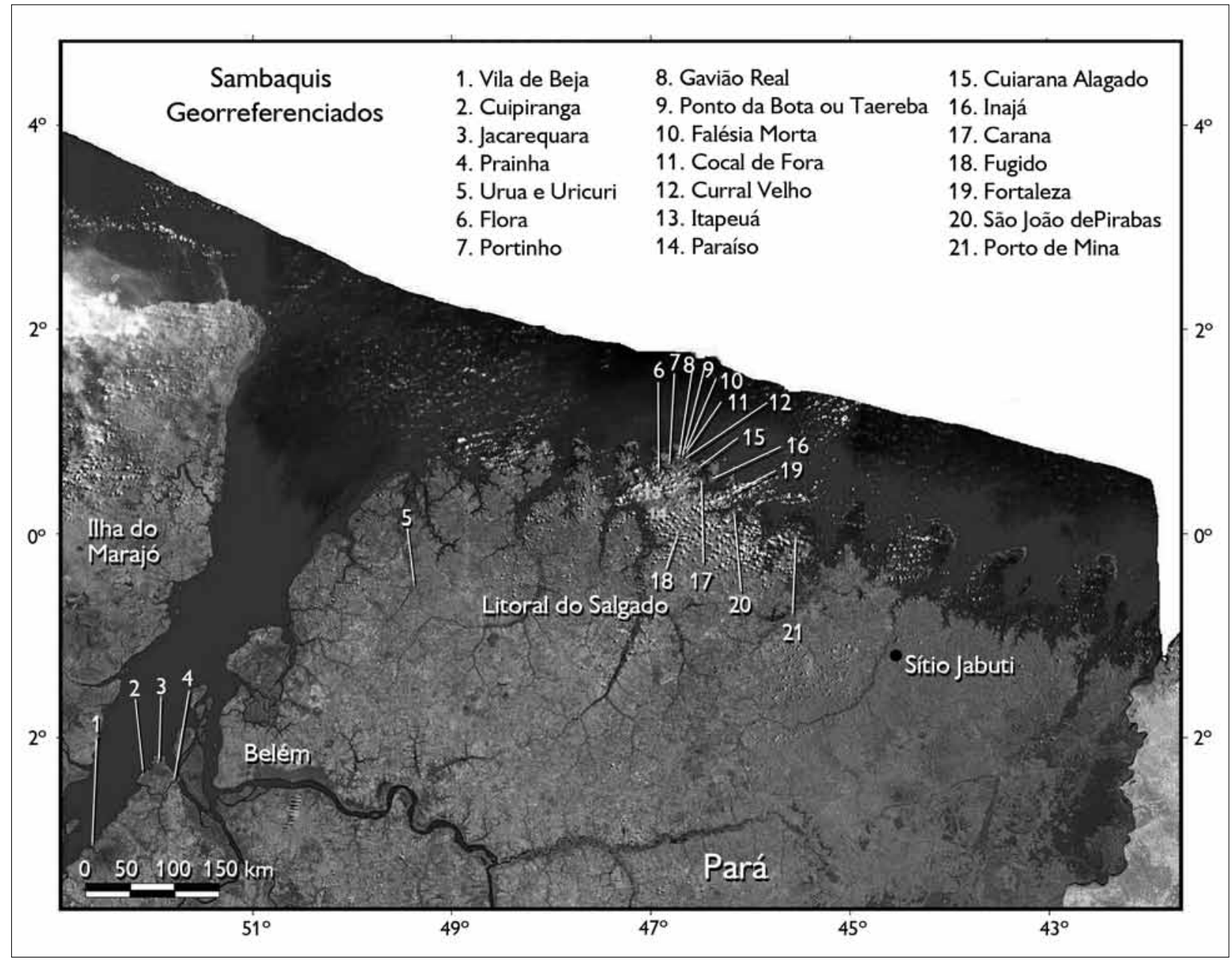

Figura 1. Imagem de satélite da região leste do estuário do Amazonas e do Salgado Paraense, com a localização dos sambaquis registrados e do sítio Jabuti.

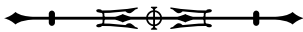


Parte integrante da zona costeira, com rios, mangues e planaltos rebaixados da costa norte brasileira (Barbosa e Pinto, 1973), a região do Salgado é composta por uma miríade de ambientes, entre os quais dunas, mangues, praias, campos salinos e matas, que propiciaram e continuam propiciando grande variedade de recursos para subsistência de grupos humanos, obtidos por meio da pesca, coleta e/ou caça. No passado, essa ampla diversidade de ambientes e recursos certamente contribuiu significativamente para fixação de assentamentos humanos.

Vestígios de ocupações humanas pré-coloniais têm sido registrados nesta área desde o final do século XIX, a maior parte deles relacionada a um tipo específico de sítio arqueológico denominado sambaqui. Nesse período, devido à intensa exploração dos depósitos de conchas para obtenção de cal, estes sítios arqueológicos foram popularmente denominados de 'minas' ou 'concheiros'.

Os sambaquis apresentam-se, geralmente, sob a forma de colinas de base oval ou circular, possuindo dimensões diversas, área aproximada variando entre $2.000 \mathrm{~m}^{2}$ por $2 \mathrm{~m}$ de altura, podendo atingir, em casos excepcionais, $126.000 \mathrm{~m}^{2}$ por $30 \mathrm{~m}$ de altura, como ocorre no estado de Santa Catarina. Neles, os vestígios mais evidentes são as conchas de moluscos, que ocorrem em grandes quantidades. Além de restos alimentares, são encontrados sepultamentos, artefatos líticos, adornos, cerâmica e vestígios de moradias, tais como pisos, buracos de esteio e estacas, resquícios de atividades cotidianas/ etapas de confecção de objetos, por exemplo, que geralmente estão alojados em solos de coloração muito escura. Nos sambaquis da Amazônia, os fragmentos cerâmicos encontrados estão associados às populações que os construíram, diferentemente do que ocorre nos sambaquis localizados no sul e sudeste do Brasil. No Pará, verifica-se, ainda, um tipo específico de vegetação que cresce sobre o sambaqui e que, juntamente com a elevação, facilita sua localização.

Contudo, sítios arqueológicos relacionados a grupos ceramistas não sambaquieiros também foram localizados tanto na faixa costeira quanto em terras do interior do litoral paraense. Estes sítios, assim como os sambaquis, foram pouco pesquisados e, portanto, não existem muitos dados disponíveis com relação à origem e ao desenvolvimento dos respectivos grupos humanos (Corrêa, 1985; Corrêa e Simões, 1971; Simões, 1981).

Assim sendo, com relação à ocupação pré-colonial do litoral paraense, permanecem em aberto questões quanto ao processo de formação dos sítios arqueológicos, à organização social, às estratégias de subsistência, aos padrões de assentamento, à natureza e à intensidade de possíveis relações entre os grupos sambaquieiros e os não sambaquieiros.

\section{GRUPOS SAMBAQUIEIROS}

De acordo com Simões (1981), a primeira referência a sambaquis litorâneos no estado do Pará foi feita por José Monteiro de Noronha, em texto escrito em 1768 e publicado em 1856, com a descrição da ocorrência de grandes minas às margens dos rios Maracanã e Marapanim.

A este relato, seguiram-se outras breves descrições de viajantes e naturalistas acerca do que era encontrado em meio às camadas de conchas durante a retirada do material para a queima em fornos. São os casos das de Charles Frederick Hartt (1885), de João Barbosa Rodrigues (1876) e de Domingos Soares Ferreira Penna, que em 1876 publicou nota informando sobre sete concheiros localizados entre as baías de Salinas e Japerica. Além de descrever os materiais encontrados, Ferreira Penna se preocupou em registrar de maneira sistemática a localização, as dimensões e a forma dos sambaquis, disponibilizando, assim, os primeiros dados detalhados sobre este tipo de sítio (Ferreira Penna, 1876).

Desta forma, nenhum trabalho sistemático coordenado por arqueólogos foi realizado nesta região até a década de 1960, quando os pesquisadores Mário Ferreira Simões e Conceição Gentil Corrêa, ambos do Museu Paraense Emílio Goeldi (MPEG), iniciaram o Projeto Salgado. Este projeto objetivou o estabelecimento de sequências do desenvolvimento cultural e temporal 
da ocupação humana pré-colonial no litoral do Pará, a tentativa de reconstruir padrões de subsistência adotados por estas sociedades e a análise comparativa dos dados aí obtidos com aqueles disponíveis em complexos similares, localizados na Guiana, Colômbia, Venezuela e nos estados do Maranhão e da Bahia (Simões, 1981).

A equipe de Simões e Corrêa identificou 43 sambaquis litorâneos, três sambaquis fluviais e 16 sítios relacionados a grupos ceramistas (Corrêa, 1985; Corrêa e Simões, 1971; Simões, 1981). Os sambaquis se encontram distribuídos por toda a região do Salgado e, de maneira geral, situam-se às margens dos rios, dos furos, das ilhas e na parte interna das baías, quase sempre cercados por manguezais (Simões, 1981, p. 12). A partir da realização de cortes estratigráficos experimentais em alguns destes sítios, foram coletadas amostras de artefatos cerâmicos, líticos, ósseos e de conchas, além da evidenciação de fogueiras e sepultamentos (Simões, 1981).

Também foi identificada uma indústria cerâmica distinta da relacionada aos grupos não sambaquieiros précoloniais, definida por meio da análise de alguns atributos tecnológicos e decorativos como fases Uruá (sambaquis fluviais) e Mina (sambaquis litorâneos), pertencentes à tradição arqueológica Mina. Os elementos diagnósticos da fase Mina são o uso de conchas moídas e areia como tempero para confecção das vasilhas cerâmicas, o emprego do engobo vermelho como decoração e o predomínio de formas simples do tipo tigelas nas vasilhas (Simões, 1981). Datações por C14 entre 5.570 e 3.490 anos AP, obtidas em amostras de conchas provenientes do tempero da cerâmica e de carvão oriundas dos sítios Ponta das Pedras, Porto da Mina e Uruá (Gaspar e Silveira, 1999; Simões, 1981; Roosevelt, 1995), posicionaram a tradição Mina como um dos complexos cerâmicos mais antigos do continente americano (Roosevelt, 1995).

Analisada em conjunto com datações igualmente recuadas, provenientes de sambaquis da Guiana relacionados à fase Alaka (entre 5.965 e 4.115 anos AP no sítio Barambina) e do baixo Amazonas (entre 6.300 e 7.500 anos AP no sítio Taperinha), a antiguidade dos sambaquis cerâmicos do litoral do Salgado contribuiu de forma incisiva na estruturação da revisão dos paradigmas até então dominantes quanto ao desenvolvimento da ocupação humana pré-colonial na região amazônica (Roosevelt, 1995; Roosevelt et al., 1991, 1996; Silveira e Schaan, 2005; Bandeira, 2008).

Outro fato que também corrobora a antiguidade dessas ocupações é o registro de vestígios arqueológicos associados à megafauna (fragmentos de costela de toxodonte) no sambaqui Fugido (Silveira, 1996). Como, na região do Salgado, encontram-se jazidas fossilíferas da formação geológica Pirabas (Ferreira e Cunha, 1957; Góes et al., 1990; Maury, 1925; Ramos et al., 2004; Rossetti e Góes, 2004; Távora, 1998), as perguntas iniciais são as seguintes: as populações sambaquieiras foram contemporâneas da megafauna encontrada nesta região? As populações sambaquieiras coletavam matéria-prima em jazidas paleontológicas? O sítio está assentado sobre uma jazida paleontológica? Sabemos que, isoladamente e descontextualizado, este fato não diz muita coisa, contudo vale a pena chamar atenção para este achado, que é no mínimo inusitado! Somente após pesquisas, poderemos tecer comentários a esse respeito.

Em consequência das flutuações do nível do mar ocorridas durante o Holoceno, há a possibilidade de se encontrar, no litoral, sítios que foram invadidos pelas águas. Desta forma, a identificação de sambaquis submersos, conhecidos na região como "minas afogadas" (Silveira, 1996), é outro fator que nos leva a supor a existência de sambaquis, no litoral e mesmo no estuário, tão ou mais antigos que Taperinha, localizado no baixo Amazonas, nas proximidades de Santarém (Roosevelt et al., 1996).

\section{GRUPOS CERAMISTAS NÃO SAMBAQUIEIROS}

A proximidade de áreas com diversos ambientes onde existe maior concentração de recursos favoreceu também a fixação de outros grupos ceramistas que, de alguma forma, estavam relacionados aos sambaquis. 
Todavia, há cerca de 2.000 anos, ou seja, em torno do ano 1, observa-se um abandono dos sambaquis e uma mudança nas estratégias de subsistência em direção ao desenvolvimento de cultivos.

Os sítios relacionados a grupos ceramistas não sambaquieiros, conhecidos à época do Projeto Salgado (total de 16 até o final da década de 1970), concentram-se na região entre os municípios de Primavera e Quatipuru (Corrêa, 1985; Simões, 1981). Porém, os poucos assentamentos existentes entre as baías de Marapanim e do Caeté indicam uma dispersão destes grupos por toda a área do Salgado.

De maneira geral, os sítios se localizam em todos os ambientes, como dunas, campos e floresta. Por meio de análise comparativa da estrutura dos assentamentos, dos vestígios associados e das datações absolutas disponíveis, os coordenadores do Projeto Salgado inferiram que estes eram grupos distintos dos ocupantes dos sambaquis. Segundo Corrêa (1985), com relação ao material cerâmico, os grupos não sambaquieiros dispunham de artefatos mais elaborados tecnologicamente, se comparados com os vestígios identificados nos sambaquis. Além disso, a opção por modos distintos de vida, evidenciados pelas diferentes utilizações dos recursos naturais disponíveis, também aponta para grupos socioculturais distintos.

As poucas datações disponíveis referentes a estes sítios arqueológicos posicionam esta ocupação entre os séculos III e XVII (fase Tucumã entre 228 e 1380 AD; fase Tijoca em 1610 AD; e fase Areão em 1430 AD), portanto, em período posterior à ocupação sambaquieira (Corrêa, 1985, p. 209-212). Outro dado relevante acerca da ocupação dos grupos não sambaquieiros é o fato de que, aparentemente, a indústria cerâmica relacionada a estes sítios não apresenta semelhança com qualquer outra da bacia amazônica. As fases identificadas, Marudá, Quatipuru, Tucumã, Mururé, Tijoca e Areão (Corrêa, 1985; Corrêa e Simões, 1971), se constituem em manifestações locais, inclusive apresentando pouca similaridade entre si (Corrêa, 1985).
Todavia, tais afirmações não puderam ser corroboradas ou refutadas à luz de novos dados, uma vez que, após a conclusão do Projeto Salgado, durante quase 40 anos não houve pesquisas arqueológicas sistemáticas na região, seja referente aos sambaquis, seja aos grupos não sambaquieiros. O estudo destes sítios e de sua evolução ao longo do tempo nos permitirá conhecer as mudanças ecológicas que ocorreram nestes ambientes e a maneira pela qual os grupos humanos responderam a essas mudanças.

Assim sendo, no início do século XXI, arqueólogos voltaram a pesquisar a região do Salgado e, neste processo de retomada do estudo das antigas populações litorâneas, foi identificado o sítio arqueológico Jabuti (Silveira et al., 2010).

\section{SÍTIO ARQUEOLÓGICO JABUTI (PA-SA-75)}

O sítio Jabuti foi descoberto pelos pesquisadores Ulf Mehlig e Moirah Menezes (Universidade Federal do Pará, campus de Bragança), que coordenam projetos de pesquisa botânica e zoológica na área da Reserva Extrativista Marinha Caeté-Taperuçu e informaram o achado de fragmentos cerâmicos durante suas pesquisas de campo. Foi registrado em 2008 como sítio arqueológico cerâmico a céu aberto devido à presença de fragmentos cerâmicos em superfície e em profundidade, apresentando solos do tipo Terra Preta Arqueológica (TPA) (Silveira et al., 2010).

Localiza-se na margem esquerda do rio Caeté, em uma ilha de terra firme situada em campo salino no litoral Bragantino, distando $36 \mathrm{~km}$ do litoral e $240 \mathrm{~km}$ da cidade de Belém (coordenadas 4640' 19.8” W / $0^{\circ}$ 55' 39.5" S, com margem de erro de $5 \mathrm{~m}$, South America Datum 69). A região de Bragança está situada nas planícies elevadas da península Bragantina, sobreposta a rochas sedimentares da Formação Pirabas e do Grupo Barreiras. Ao longo da costa, predominam sedimentos de idade quaternária, areias de praias, argilas de manguezais e várzeas, portanto, de zonas inundáveis (Pará, 2007b).

O clima da região é do tipo Aw na classificação de Köppen, de reduzida amplitude térmica, com índice pluviométrico anual de cerca de 2.100 mm, com 90\% 
dessa pluviosidade distribuída nos seis primeiros meses do ano, definidos como o inverno (Rede..., 2008).

Segundo Piccinin (2009), na paisagem regional e/ ou local são encontrados diversos ambientes que incluem mangue, campos salinos, bosques de terra firme e praias. Apenas estes três últimos compõem a paisagem atual da área do sítio. Verificou-se que ocorreu, em décadas passadas, a retirada da vegetação primária para formação de pastagens destinadas à pecuária, pois hoje, na área do sítio Jabuti, crescem capoeira e florestas secundárias com grande quantidade de palmeiras, principalmente das espécies inajá (Maximiliana regia) e babaçu (Orbignya oleifera). A floresta original, ainda remanescente em pequenos tratos isolados, corresponde ao tipo geral das Florestas Tropicais Úmidas, subtipo Floresta Densa. Nas áreas sujeitas à inundação, predominam os manguezais com suas espécies características, como siriúba (Avicennia nitida) e mangueiro (Rhizophora mangle).
Nas áreas onde foi realizado o levantamento arqueológico, os solos são caracterizados como mal a muito mal drenados, com forte gleização e sequência de horizontes A-Cg. Nas áreas do entorno do sítio, os solos apresentam características intrínsecas de horizonte A moderado e fraco, pouco espesso e muito arenoso. Com a subtraçãa da vegetação, esses solos tornaramse altamente suscetíveis aos processos de modificação morfoestrutural, caracterizados por um estado estrutural sem qualquer coesão de partículas nos primeiros $15 \mathrm{~cm}$ de profundidade, fator agravado pelas queimadas que se sucederam no decorrer dos anos (Piccinin, 2009).

No trabalho de delimitação do sítio Jabuti, realizado em 2008, efetuou-se a verificação da extensão e profundidade da ocorrência de vestígios arqueológicos. Foram vistoriadas e limpas duas áreas onde já existiam dois buracos abertos no solo, denominados de sondagens/ perfis 1 e 2 (Figuras 2 e 3). Também foi selecionada uma

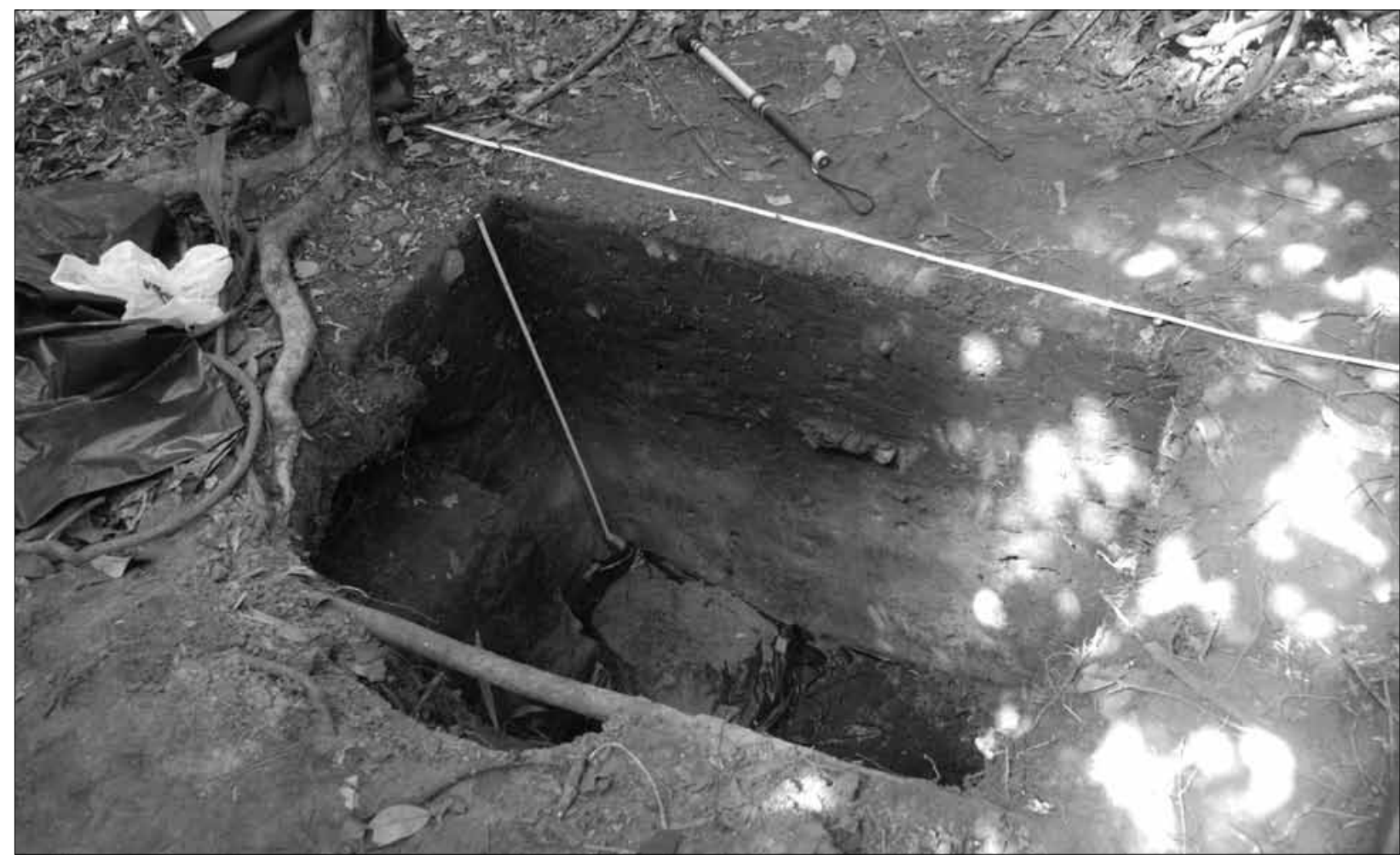

Figura 2. Perfil 1. Observa-se a profundidade da TPA e dos vestígios arqueológicos. Foto: Ulf Mehlig.

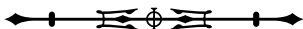




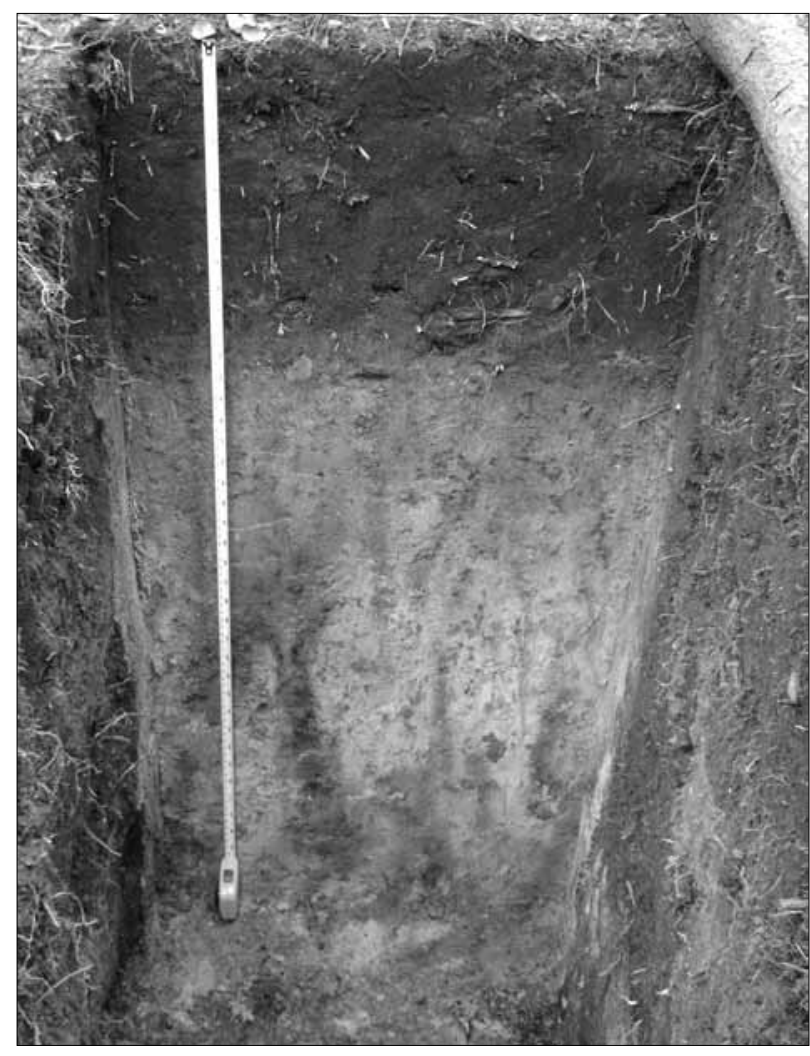

Figura 3. Perfil 2. Ocorrência de TPA em profundidade menor, se comparado ao perfil 1. Foto: Maura Imazio da Silveira.

área de 100 m x 100 m, na qual foram abertas picadas em malha ortogonal com espaçamento regular de $20 \mathrm{~m}$, ou seja, um quadriculamento com transectos perpendiculares e paralelos ao mangue.

Nesta malha (Figura 4), as tradagens foram efetuadas, inicialmente, com espaçamento regular de $20 \mathrm{~m}$, porém percebeu-se que o sítio é composto por diversas manchas de TPA e não por uma única mancha contínua. Assim sendo, o intervalo entre as tradagens foi diminuído para $10 \mathrm{~m}$, o que possibilitou a identificação de seis manchas com tamanhos e profundidades variadas. Por fim, ao redor das sondagens/perfis 1 e 2 , realizou-se tradagens nas direções N, S, E e W, de metro em metro, o que permitiu delimitar e examinar a profundidade dessas duas manchas de TPA. Com relação às demais manchas, foi verificada sobreposição entre algumas, o que sugere, a princípio, remanejamento de áreas de habitação ou reocupação da área em períodos distintos (Silveira et al., 2010).

$\mathrm{Na}$ análise da estratigrafia das sondagens/perfis, foi observado que a camada de TPA é mais profunda no perfil 1 e mais delgada no perfil 2, variando entre $90 \mathrm{~cm}$ e $40 \mathrm{~cm}$ de profundidade, respectivamente. $\bigcirc$ material arqueológico coletado constitui-se, principalmente, de fragmentos de cerâmica (aproximadamente 850), alguns artefatos líticos lascados e corantes. Observou-se nos dois perfis uma camada de transição entre a TPA e a camada estéril, identificada como 2C, provavelmente relacionada ao início da ocupação. Nesse primeiro momento da pesquisa, na camada estéril não se encontraram mais vestígios arqueológicos. Contudo, como em outros sítios, em seu topo ainda é possível observar algum tipo de intrusão proveniente do início da ocupação, como, por exemplo, buracos de esteio ou estaca, fogueiras cavadas, entre outros. Deve-se ressaltar que na área adjacente ao sítio foi feita uma terceira sondagem/perfil, utilizada como referência comparativa para as análises de solo e para a interpretação do processo de formação do sítio.

O resultado da única datação por C14 indica que o sítio Jabuti foi ocupado há pelo menos 2.900 anos BP (cal BC 1106, 1104, 1050). O carvão, proveniente do perfil 1, estava localizado no contexto da camada de ocupação, identificada como 2 e subdividida em 2A, 2B e 2C. A julgar pela profundidade em que foi coletado $(70 \mathrm{~cm})$, corresponde à camada $2 \mathrm{C}$, identificada como o período inicial da ocupação.

A caracterização preliminar do sítio Jabuti permite classificá-lo como cerâmico a céu aberto do tipo habitação, com manchas de TPA. Os sítios habitação caracterizam-se por serem áreas ocupadas por longo período, continuamente ou não, onde é registrada presença de terra preta arqueológica (TPA) ou de solo muito escuro, que apresenta variações quanto à profundidade, de $60 \mathrm{~cm}$ a mais de $1 \mathrm{~m}$, e tipo de ocorrência, em manchas ou contínua. Nos solos com TPA, em geral, é encontrada grande quantidade de 


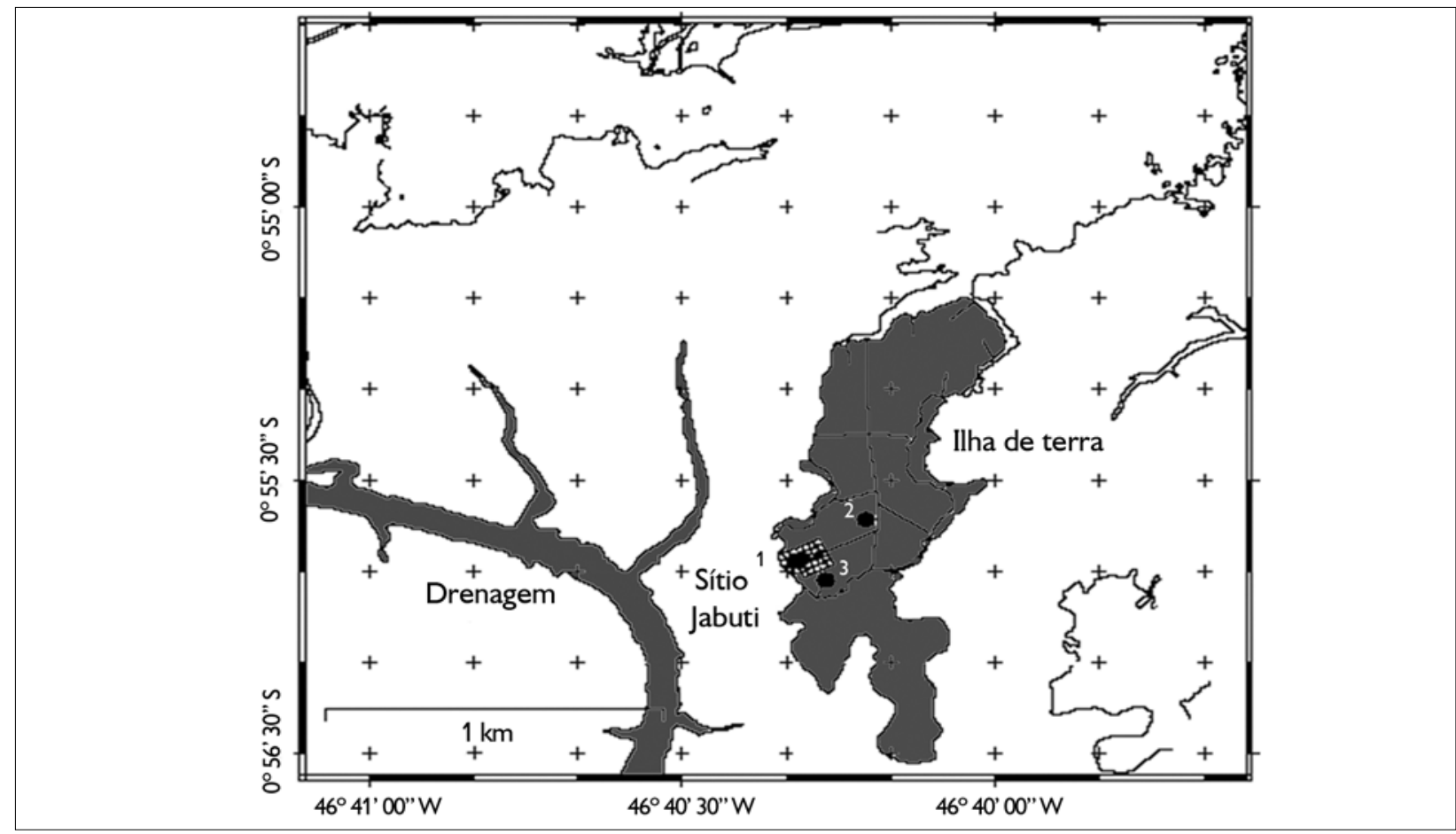

Figura 4. Croqui indicando a rede de drenagem e, ao centro, a maior ilha de terra onde está situado o sítio Jabuti, podendo-se observar a malha das tradagens e a localização das sondagens/perfis realizadas.

material arqueológico, principalmente cerâmica, em superfície e em profundidade. Observa-se, ainda, que certos vestígios, algumas vezes, ocorrem concentrados em partes específicas do assentamento, indicando prováveis áreas de atividade, que apresentam teores elevados de nutrientes ( $\mathrm{Ca}, \mathrm{Mg}$ e $\mathrm{P}$ ) e micronutrientes (Zn e Mn) (Kämpf e Kern, 2005; Silveira et al., 2009; Petersen et al., 2001; Neves et al., 2003).

As características observadas no material cerâmico deste sítio remetem à tradição Mina. Na análise preliminar de laboratório, verificou-se nos fragmentos o uso isolado ou em associação de antiplástico dos tipos concha, carvão, caco moído, areia, caraipé (cariapé) e mica. A técnica de manufatura predominante é o acordelado. Quanto ao tratamento de superfície, a maioria dos fragmentos é simples e as decorações mais comuns são escovado, inciso, engobo vermelho e branco (Figura 5). É importante frisar que, a princípio, não foi verificada ocorrência de moluscos e ossos de peixes no sedimento, ou seja, não se trata de um sambaqui, mas de um sítio cerâmico com TPA, provavelmente relacionado a grupos que praticavam algum tipo de cultivo.

Neste contexto, ainda que preliminarmente, foram levantadas três hipóteses: 1) a ocorrência de cerâmica Mina neste tipo de sítio arqueológico pode indicar alguma forma de contato (trocas, casamentos, domínio etc.) entre grupos sambaquieiros e outros grupos ceramistas; 2) mudança na economia e no modo de vida dos grupos sambaquieiros em direção ao cultivo; ou, ainda, 3) os sítios integrariam um mesmo sistema de assentamento apresentando funções diferenciadas.

Segundo Souza Filho et al. (2009), a área física da Reserva Extrativista (RESEX) Marinha Caeté-Taperuçu, na zona Bragantina do litoral do Salgado, onde se situa o sítio Jabuti, teve início a partir de 5.900 cal anos AP, com a formação da primeira barreira (ilha de terra maior) 


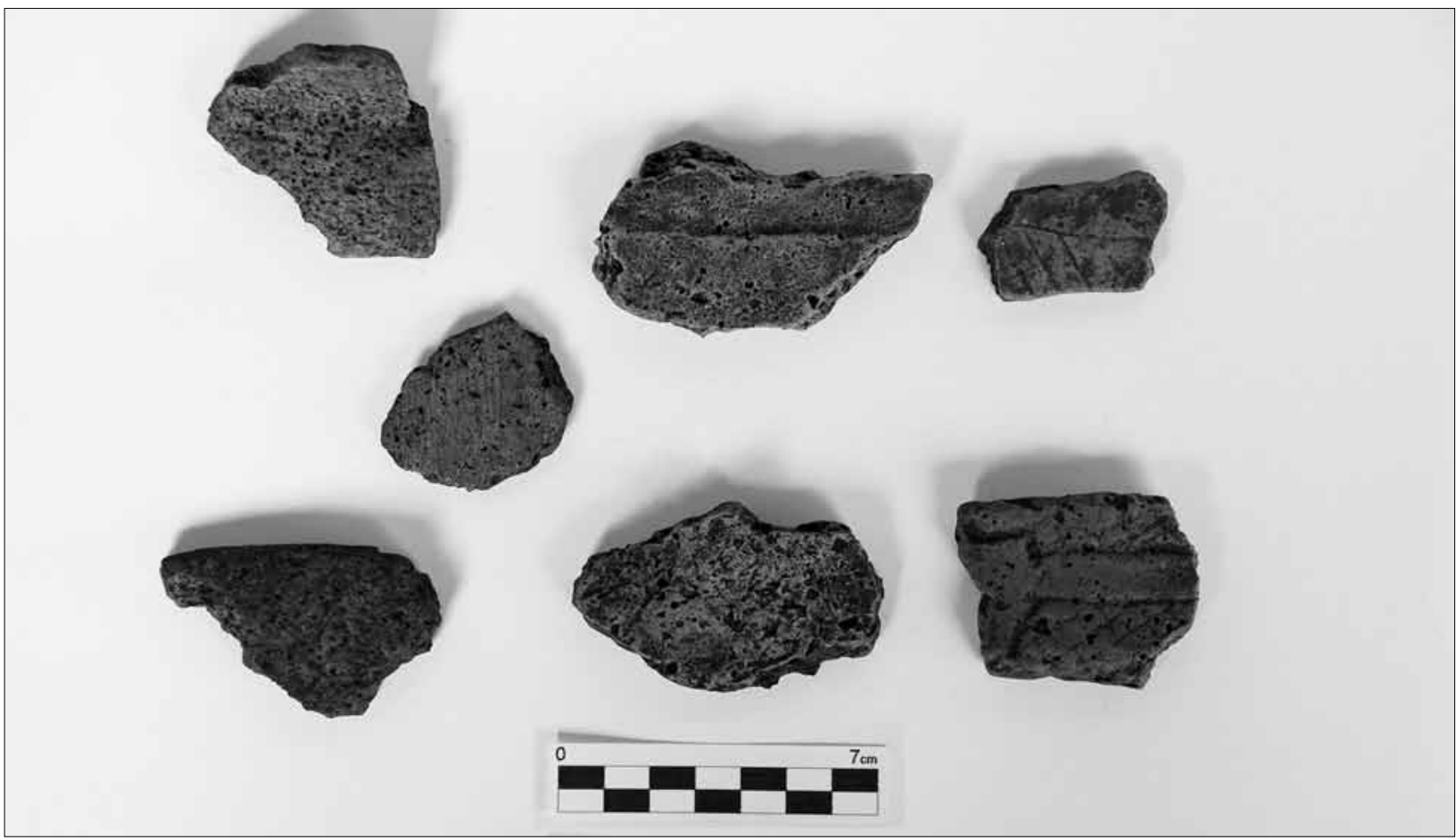

Figura 5. Fragmentos cerâmicos identificados no sítio Jabuti. Cerâmica de espessura fina, queima incompleta e temperada com conchas moídas. Foto: Paula Sampaio.

próxima ao continente. De 3.736 a 2.800 cal anos AP formou-se a segunda barreira (ilha de terra menor), em frente da primeira e mais distante do continente. Em seguida, de 2.100 a 1.350 cal anos AP formaram-se os campos salinos entre as duas barreiras (ilhas de terra) e o continente. Por último, de $1.000 \mathrm{cal}$ anos AP ao presente formou-se a terceira barreira (ilha de terra). Interessante notar que, segundo a datação obtida no sítio Jabuti, ao redor de 2.900 anos antes do presente, a ocupação deste sítio ocorreu no segundo momento desse modelo, ou seja, o sítio estava situado na maior ilha de terra, próximo ao continente, e seus habitantes possivelmente testemunharam a formação da segunda barreira (ilha de terra) e dos campos salinos.

Contudo, para a formulação de um modelo de ocupação do sítio Jabuti, faz-se necessário aprofundar as pesquisas arqueológicas. Os dados deste modelo arqueológico poderão contribuir para aprimorar o entendimento do processo de formação do sítio e também para a localização de outros assentamentos pré-coloniais na costa do Pará e Maranhão, ampliando o conhecimento sobre o povoamento pré-histórico local e regional.

Os resultados preliminares das análises de solos realizadas no perfil 1 (com TPA) e no perfil 3 (localizado em área adjacente) indicaram que esses solos são constituídos predominantemente por quartzo e matéria orgânica, sendo acessórios caulinita, mica e anatásio. São, portanto, muito ricos em SiO2 e contém, ainda, $\mathrm{P} 2 \mathrm{O} 5, \mathrm{Al} 2 \mathrm{O} 3, \mathrm{Fe} 2 \mathrm{O} 3, \mathrm{TiO} 2$ e $\mathrm{MnO}$. No perfil com TPA, o manganês se concentra preferencialmente nos oxi-hidróxidos de ferro amorfos e na fase residual, esta última também registrada no perfil da área adjacente (Lima et al., 2010).

Os fragmentos cerâmicos provenientes do perfil 1 são constituídos pelos minerais básicos da matéria prima, como argila, representada por metacaulinita,

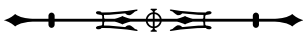


quartzo, mica e, por vezes, anatásio. Ocorrem, ainda, crandallita-goyazita e fosfatos de alumínio. Desta forma, a composição química dos fragmentos cerâmicos é também dominada por $\mathrm{SiO} 2, \mathrm{Al} 2 \mathrm{O} 3$ e $\mathrm{P} 2 \mathrm{O} 5$, além de $\mathrm{CaO}$ e SrO. No entanto, o dado que mais chamou a atenção foram os elevados teores de fósforo $(P)$ presentes nos fragmentos, até o momento os mais elevados conteúdos de $P$ já identificados em fragmentos cerâmicos de sítios arqueológicos localizados na Amazônia (Costa et al., 2010; Rodrigues et al., 2010).

A ocupação pretérita da Amazônia é um tema que interessa não apenas a pesquisadores, mas também à sociedade como um todo. Porém, enormes áreas permanecem desconhecidas ou pouco estudadas e várias questões foram apenas delineadas. Espera-se, com o desenvolvimento das pesquisas neste tipo de sítio, contribuir com dados para ampliar a compreensão da ocupação humana nesses ambientes ricos em recursos naturais, como também com as discussões sobre o povoamento pretérito do litoral amazônico.

\section{AGRADECIMENTOS}

A equipe desta pesquisa, inicialmente realizada no âmbito do projeto "Potenciais Impactos Ambientais do Transporte de Petróleo e Derivados na Zona Costeira Amazônica" (PIATAM Mar), e sob a chancela do Programa de Estudos Costeiros do MPEG, é formada por Dra. Dirse Kern e Dr. Jorge Piccinin, especialistas em TPA; Dr. Marcondes Lima da Costa e sua equipe, que estão realizando análises químicas e mineralógicas da cerâmica; Dra. Moirah Menezes e Dr. Ulf Mehlig, que trabalham com os aspectos botânicos na área do sítio; e MSc. Elisângela Oliveira, que está estudando a cerâmica. Os autores agradecem a todos os que participaram dos trabalhos de pesquisa, em especial a Fernanda Araújo Costa, pela revisão do manuscrito, além do apoio das instituições Conselho Nacional de Desenvolvimento Científico e Tecnológico, Scientia Consultoria, Museu Paraense Emílio Goeldi e Universidade Federal do Pará.

\section{REFERÊNCIAS}

BANDEIRA, Arkley Marques. Ocupações humanas pré-históricas no litoral maranhense: um estudo arqueológico sobre o sambaqui do Bacanga na ilha de São Luis-Maranhão. 2008. 173 f. Dissertação (Mestrado em Arqueologia) - Museu de Arqueologia e Etnologia, Universidade de São Paulo, São Paulo, 2008.

BARBOSA, G. V.; PINTO, M. N. Geomorfologia da Folha SA-23 (São Luis) e parte SA-24 (Fortaleza). In: BRASIL. Departamento Nacional de Produção Mineral. Projeto Radam Brasil. Folha SA-23 São Luís e parte da Folha SA-24 Fortaleza: geologia, geomorfologia, solos, vegetação e uso potencial da terra. Rio de Janeiro, 1973. p. 3-37.

BARBOSA RODRIGUES, J. Antiguidades do Amazonas. Sernambys. Ensaios de Sciencia, Rio de Janeiro, 4, p. 23-34, 1876.

CORRÊA, Conceição M. G. Fases ceramistas não-sambaquieiras do litoral do Pará. 1985. 220 f, il. Dissertação (Mestrado) Universidade Federal de Pernambuco, Recife, 1985.

CORRÊA, Conceição M. G.; SIMÕES, Mário Ferreira. Pesquisas arqueológicas na região do Salgado. A fase Areão do litoral de Marapanim. Boletim do Museu Paraense Emílio Goeldi, Nova Série Antropologia, n. 48, p. 10-30, jul. 1971.

COSTA, Marcondes Lima; SOUZA DA SILVA, Glayce Jholy; RODRIGUES, Suyanne Flávia Santos; COSTA, Jucilene Amorim; KERN, Dirse Clara; CARVALHO, Mônia. Os fragmentos cerâmicos como fonte continuada de nutrientes e micronutrientes para os solos de TPA. In: WORKSHOP TERRA PRETAARQUEOLÓGICA(TPATTPN), 1., 2010, Belém. Resumos... Belém: MPEG/UFPA, 2010. p. 2-4.

FERREIRA, C. S.; CUNHA, O. R. Contribuição à paleontologia do estado do Pará. Notas sobre a Formação Pirabas, com descrição de novos invertebrados fósseis (Mollusca - Gastropoda). Boletim do Museu Paraense Emílio Goeldi, Nova Série Geologia, n. 2, p. 1-60, 1957.

FERREIRA PENNA, Domingos Soares. Breve notícia sobre os sambaquis do Pará. Archivos do Museu Nacional, Rio de Janeiro, v. 1 , p. $85-99,1876$

GASPAR, Maria Dulce; SILVEIRA, Maura Imazio. Os pescadorescoletores-caçadores do litoral Norte brasileiro. In: TENÓRIO, Maria Cristina (Org.). Pré-História da Terra Brasilis. Rio de Janeiro: Universidade Federal do Rio de Janeiro, 1999. p. 247-260.

GÓES, A. M.; ROSSETTI, D. F.; NOGUEIRA, A. C. R.; TOLEDO, P. M. Modelo deposicional preliminar para a Formação Pirabas, nordeste do Estado do Pará. Boletim do Museu Paraense Emílio Goeldi, série Ciências da Terra, v. 2, n. 1, p. 3-15, 1990.

HARTT, Charles F. Contribuições para a ethnologia do valle do Amazonas. Archivos do Museu Nacional do Rio de Janeiro, v. 6, p. 1-174, 1885.

KÄMPF, Nestor; KERN, Dirse Clara. O solo como registro da ocupação humana pré-histórica na Amazônia. Tópicos em ciência do solo. 1. ed. Viçosa: Sociedade Brasileira de Ciência do Solo, 2005. v. VI, p. 277-320.

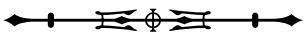


LIMA, Wivian Thaís dos Santos de; LEMOS, Vanda Porpino; KERN, Dirse Clara. Disponibilidade do manganês em TPA do sítio Jabuti - Bragança (Pará). In: WORKSHOP TERRAPRETAARQUEOLÓGICA(TPATTNN), 1., 2010, Belém. Resumos... Belém: MPEG/NFPA, 2010. p. 72-76.

MAURY, C. J. Fósseis terciários do Brasil com descripção de novas formas cretáceas. Monographia do Serviço Geológico e Mineralógico do Brasil, n. 4, p. 1-665, 1925.

NEVES, Eduardo G.; PETERSEN, James B.; BARTONE, R. N.; SILVA, C. A. Historical and socio-cultural origins of Amazonian Dark Earths. In: LEHMANN, Johannes; KERN, Dirse C.; GLASER, Bruno; WOODS, William I. (Eds.). Amazonian Dark Earths. Origin, properties and management. Norwell: Kluwer Academic Publishers, 2003. p. 29-50.

NORONHA, José Monteiro de. Roteiro de viagem da cidade do Pará até as ultimas colonias dos dominios portuguezes em os rios Amazonas e Negro. In: Colleções de noticias para a Historia e Geographia das Nações Ultramarinas que vivem nos domínios portuguezes. Academia Real das Sciencias, Lisboa, n. 6, p. 1-85, 1856.

PARÁ. Secretaria Especial de Gestão. Diretoria de Estudos, Pesquisas e Informações Sócio-Econômicas. Estatística municipal de São João de Pirabas. Belém, 2007a. Disponível em: <http://www.sepof. pa.gov.br>. Acesso em: 11 jun. 2007.

PARÁ. Secretaria de Estado de Planejamento, Orçamento e Finanças (SEPOF). Belém, 2007b. Disponível em: < http://www.sepof.pa.gov. br>. Acesso em: 11 jun. 2007.

PETERSEN, James B.; NEVES, Eduardo G.; HECKENBERGER, Michael J. Gift from the past: Terra Preta and prehistoric Amerindian occupation in Amazonia. In: MCEWAN, Colin; BARRETO, Cristiana; NEVES, Eduardo G. (Eds.). Unknown Amazon. London: The British Museum Press, 2001. p. 86-105.

PICCININ, Jorge L. Análise estrutural da cobertura pedológica Terra Preta Arqueológica (TPA). Sítio Jabuti - Bragança - PA. Relatório de pesquisa. Belém: Museu Paraense Emílio Goeldi, 2009. 11 p.

RAMOS, M. I. F.; TÁVORA, V. A.; PINHEIRO, M. P.; BAIA, N. B. Microfósseis. In: ROSSETTI, D. F.; GÓES, A. M. (Eds.). Neógeno da Amazônia Oriental. Belém: Museu Paraense Emílio Goeldi, 2004. p. 93-107.

REDE ESTADUAL DE PREVISÃO CLIMÁTICA E HIDROMETEOROLÓGICA DO PARÁ. Boletim de Análise e Previsão Climática, ano 2, n. 17, 2008. Disponível em: <http:// www.ufpa.br/rpch/produtos/Boletim_RPCH_AnolI_No17 Mai2008.pdf>. Acesso em: 10 set. 2008.

RODRIGUES, Suyanne Flávia Santos; COSTA, Marcondes Lima da; SILVEIRA, Maura Imazio da; KERN, Dirse Clara; MENEZES, Moirah; MEHLIG, Ulf; GOESKE, Juergen. Identificação e caracterização dos fosfatos de fragmentos cerâmicos do sítio jabuti, Bragança-PA. In: WORKSHOP TERRA PRETA ARQUEOLÓGICA (TPA/TPN), 1. 2010, Belém. Resumos... Belém: MPEG/UFPA, 2010. p. 115-120.
ROOSEVELT, Anna C. Early pottery in the Amazon. Twenty years of scholarly obscurity. In: BARNETT, W. K.; HOOPES, John W. (Ed.). The emergence of pottery. Technology and innovation in ancient societies. Washington: Smithsonian Institution Press, 1995. p. 115-131.

ROOSEVELT, Anna C.; COSTA, Marcondes Lima; MACHADO, Christiane Lopes; MICHAB, M.; MERCIER, N.; VALLADAS, H.; FEATHERS, James; BARNETT, William; SILVEIRA, Maura Imazio; HENDERSON, A.; SILVA, J.; CHERNOFF, B.; REESE, D. S.; HOLMAN, J. A.; TOTH, N.; SCHICK, K. Paleoindian cave dwellers in the Amazon: the peopling of the Americas. Science, v. 272, n. 5260, p. 373-384, 1996.

ROOSEVELT, Anna. C.; HOUSELEY, R. A.; IMAZIO DA SILVEIRA, Maura; MARANCA, Silvia; JOHNSON, R. Eighth millennium pottery from a prehistoric shell midden in the Brazilian Amazon. Science, $v$. 254, p. 1621-1624, 1991.

ROSSETTI, D. F.; GÓES, A. M. Geologia. In: ROSSETTI, D. F; GÓES, A. M. (Eds.). Neógeno da Amazônia Oriental. Belém: Museu Paraense Emílio Goeldi, 2004. p. 13-52.

SILVEIRA, Maura I. Relatório do Projeto Estratégias de subsistência dos grupos que ocuparam o litoral do Pará. Relatório de pesquisa. Belém: Museu Paraense Emílio Goeldi, 1996.

SILVEIRA, Maura I.; OLIVEIRA, Elisangela R.; PICCININ, Jorge L. Relatório final do Projeto PIATAM mar. Relatório de pesquisa. Belém: Museu Paraense Emílio Goeldi, 2010.

SILVEIRA, Maura I.; RODRIGUES, Maria C. L. F.; OLIVEIRA, Elisangela R. Relatório Final do Projeto de Salvamento arqueológico na área do Projeto Salobo - PA. Relatório de pesquisa. Belém: Museu Paraense Emílio Goeldi, 2009. 2 v.

SILVEIRA, Maura I.; SCHAAN, Denise P. Onde a Amazônia encontra o mar: estudando os sambaquis do Pará. Revista de Arqueologia, v. 18, p. 67-79, 2005.

SIMÕES, Mário F. Coletores-pescadores ceramistas do litoral do Salgado (Pará). Boletim do Museu Paraense Emílio Goeldi, Nova Série Antropologia, n. 78, p. 1-32, 1981.

SOUZA FILHO, Pedro W. M.; LESSA, Guilherme C.; COHEN, Marcelo C. L.; COSTA, Francisco R.; LARA, Ruben J. The subsiding macrotidal barrier estuarine system of the eastern Amazon coast, Northern Brazil. In: DILLENBURG, Sérgio F;; HESP, PatrickA. (Eds.). Geology and geomorphology of Holocene coastal barriers of Brazil. New York: Springer, 2009. p. 347-375.

TÁVORA, V. A. Ocorrência de uma nova espécie de ostracoda na Formação Pirabas (Eomioceno) - estado do Pará. Boletim do Museu Paraense Emílio Goeldi, série Ciências da Terra, v. 10, p. 3-15, 1998.

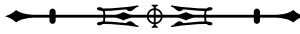

